\title{
Fast-Atom Bombardment of the Cyclic Acetals: Evidence Indicating the Predominant Involvement of Condensed-Phase Processes in Ionization
}

\author{
Gary J. C. Paul, Serge Bourg, and Michel J. Bertrand \\ Regional Center for Mass Spectrometry, Department of Chemistry, University of Montreal, Montreal, Canada
}

\begin{abstract}
A series of cyclic acetals, the 2-phenyl-1,3-dioxolanes, and their deuterated analogues were studied by electron ionization (EI), chemical ionization (CI), and fast-atom bombardment $(\mathrm{FAB})$ mass spectrometry to gain insight into the primary ionization processes for these compounds in FAB/liquid secondary ion mass spectrometry. Comparison of EI and CI data with that of FAB led to the conclusion that the predominant $[\mathrm{M}-\mathrm{H}]^{+}$ion observed in FAB for the nondeuterated cyclic acetals cannot to a large extent be rationalized in thermodynamic terms by known gas-phase ion-molecule reactions. Instead, a condensed-phase model in which the multicharged transition state for hydride abstraction is better solvated than the transition state for proton transfer appears to be a plausible explanation for the FAB data obtained for the nonlabeled cyclic acetals; however, this explanation is not entirely sufficient to rationalize the FAB data for the deuterated cyclic acetals. For these compounds, a dramatic time dependence of protonation versus hydride abstraction is observed that suggests that beam-induced reactive species are responsible for hydride abstraction in the condensed phase. This time dependence can be interpreted in terms of a buildup of highly reactive beam-induced species in the bulk of solution. Comparison of the results obtained for deuterated acetals with different surface activities support this hypothesis. (J Am Soc Mass Spectram 1993, 4, 493-503)
\end{abstract}

$\mathrm{S}$ ince its introduction in 1981, fast-atom bombardment (FAB) mass spectrometry has proved to be a powerful tool for the analysis of involatile, thermally labile compounds $[1,2]$. The technique is simple to use and in many cases the generation of protonated molecules $[\mathrm{M}+\mathrm{H}]^{+}$allows molecular mass determination for several classes of organic compounds, most of which were previously inaccessible by conventional gas-phase ionization techniques.

Although there is general agreement on the mechanism of desorption of neutral molecules from the liquid surface on FAB and the supply process that allows the analyte to be sampled by the sputtering, the question of ion formation has still not been adequately resolved [3-6]. Some investigators have provided evidence showing that ionization of the analyte occurs in the condensed phase before and/or during the bombardment process [7-9]. Resulting species can be ejected as fragments, molecular ions, or clusters, depending on the distance of the analyte molecule from the impinging fast atoms [7]. Other work has demonstrated that unimolecular decomposition of the ionic

Address reprint requests to Michel J. Bertrand, Regional Center for Mass Spectrometry, Department of Chemistry, University of Montreal, P.O. Box 6128, Station A, Montreal, Canada, H3C 3 J7. species in the gas phase can also contribute to the final FAB mass spectrum [7, 10-12]. Some investigators have obtained data that suggest that the analyte leaves the liquid surface as neutral molecules and that they subsequently undergo gas-phase ion-molecule reactions that dictate the FAB mass spectral features [13-16]. In the latter gas-phase ionization model, the protonated liquid matrix is presumed to provide the major reactant ionic species $[13,14]$. There is apparent disagreement, however, on whether the ionic precursors to the protonated matrix are generated in solution during the collision cascade created by the fast atoms $[13,14]$ or in the gas phase on collision of the atomic beam with the matrix vapor $[15,16]$. A unified theory has also been presented that incorporates qualitative aspects of both the condensed and gas-phase ionization models [11]. In this model, preformation of ions in solution prior to FAB is predicted with no subsequent reactions of the $\mathrm{FAB}$-desorbed ions in the selvedge region immediately above the liquid matrix. In addition, desorption of neutral molecules from the liquid surface on FAB is also proposed to occur, followed by gas-phase ion-molecule reactions, such as cationization in the selvedge region. It is important to remember, however, that the studies referred to involve a variety of chemical systems with different chemical 
properties that can substantially affect the extent of gas- and condensed-phase contributions to the overall FAB ionization process.

Condensed-phase ionization in FAB can be broken down into two categories: ion formation as a result of a chemical equilibrium in solution that exists without $\mathrm{FAB}$, and fast-atom beam-induced ionization that produces similar or different ionic species in solution. Ion formation by conventional chemical equilibrium has been assumed in FAB for ionic compounds [17, 18]. Product ions from condensed-phase reactions prior to FAB, such as alkali salt addition [19-21], charge-transfer complexation $[22,23]$, and electrochemical reactions [24], have all been detected in FAB mass spectra. Indeed, relationships between solution concentration and secondary ion emission have been used to evaluate crown ether-alkali cation stability constants $\lceil 20$, 21] and $p K_{a}$ values for weak acids [25]. It is important to note, however, that not all measurements of condensed-phase equilibria using FAB have been successful [26], and it has been shown that a direct relationship between acid addition and secondary ion emission in FAB is often compromised by effects such as changes in solubility, surface activity, volatility, and fast-atom beam-induced chemistry [27]. For some nonionic analytes and matrices, ionization in the condensed phase has been suggested to occur via fast-atom beam-induced processes $[8,9,22,23,28]$. One of the most comprehensive studies of this hypothesis was performed by Todd [9] who collected the liquid secondary ion mass spectra of a series of $n$-alkylamines, introduced via the gas phase on to the glycerol matrix. In those experiments, the protonated amine concentrations detected were found to be much higher than those predicted by Herry's law [9]. Hence, it was suggested that the precursors to these species were not free-base amine molecules but protonated amines in solution resulting from beam-induced processes [9]. In fact, as previously mentioned, Sunner et al. $[13,14]$ proposed that the ionic precursors to the protonated matrix ions in their gas collision model were formed in the condensed phase through fast-atom beam-induced chemistry. Fast-atom beam-induced reactions were believed responsible for the inability to evaluate the equilibrium constant for the glycine/Cu(II) system in glycerol [26].

A large body of experimental data has been collected that suggests for certain compounds that ionization mainly occurs in the gas phase in FAB. In particular, similarities in FAB and chemical ionization (CI) mass spectra, such as the predominant formation of $[\mathrm{M}+\mathrm{H}]^{+}$parent molecular ions and comparative fragmentation patterns, have been presented as evidence for the importance of gas-phase ion-molecule reactions in $\mathrm{FAB}[13,15,29,30]$. Simple vapor pressure calculations have indeed shown that a CI pressure regime exists above the liquid matrix in FAB [15]. In addition, anomalous $\mathrm{M}^{-+}$and $[\mathrm{M}-\mathrm{H}]^{+}$peaks in $\mathrm{FAB}$ for low-molecular-weight alcohols and crown ethers, respectively, are also present in the corresponding $\mathrm{CI}$ spectra [31, 32]. In a FAB study involving analyte mixtures, it was found that the mass spectral features were better explained by gas-phase basicities than by the corresponding condensed-phase data [14]. Electron ionization (EI)-type processes have also been proposed to occur in $F A B$ for a series of prenylated flavonoids in various liquid matrices to account for the $\mathrm{M}^{-+}$formation and the fragmentation observed [30,33].

Although several similarities have been observed among $\mathrm{EI}, \mathrm{Cl}$, and $\mathrm{FAB}$ data, important differences are also present. In previous reports we indicated anomalies in systems that differed between their $\mathrm{CI}$ and $\mathrm{FAB}$ behavior $[12,34,35]$. In one of these systems, the cyclic acetals [34], the dominant formation of an anomalous $[\mathrm{M}-\mathrm{H}]^{+}$species in the molecular ion region of FAB was not observed in the corresponding CI mass spectra. On the basis of the experimental data and gas-phase thermodynamic considerations, the formation of [M $\mathrm{H}^{+}$in FAB could not be rationalized in terms of known CI and EI gas-phase ionization processes [34]. In this study, the mass spectral behavior of the 2 phenyl-1,3-dioxolanes is examined in more depth, using additional cyclic acetals such as deuterated analogues to shed further light on the ionization processes involved in FAB for these compounds. Because additional classes of compounds, such as the sugars [35, 36], crown ethers [32], and molecules containing long alkyl chains [37], also yield $\left[\mathrm{M}-\mathrm{H}^{+}\right.$in $\mathrm{FAB}$, information on the $F \wedge B$ ionization processes occurring for the cyclic acetals may well relate to these systems also.

\section{Experimental}

Synthesis of the 2-phenyl-1,3-dioxolanes was achieved by condensation of benzaldehyde and benzaldehyde$\alpha-d_{1}$ with the appropriate diols [38]. The deuterated compounds were purchased from MSD Isotopes (Montreal, Canada), and the other chemicals were obtained from Aldrich Chemical Co. (Milwaukee, WI). All compounds were used without further purification except for benzaldehyde, which was redistilled to eliminate traces of benzoic acid. Thin-layer chromatography was used to isolate the final products, removing any impurities resulting from hydrolysis of the cyclic acetals. The structure and purity of the cyclic acetals were confirmed using ${ }^{1} \mathrm{H}$-nuclear magnetic resonance (Bruker WH400, Rheinstetten, Germany) and gas chromatography/mass spectrometry (VG Trio-1, Manchester, UK).

The FAB data were collected with a Kratos MS50TC triple-analyzer mass spectrometer (Kratos, Manchester, UK) arranged in a C-shaped EBE geometry [39]. The mass spectrometer was operated at an acceleration voltage of $8 \mathrm{kV}$ and a mass resolution of approximately 3000 (10\% valley definition). The $6-\mathrm{keV}$ xenon fast-atom beam was generated by an Ion Tech B11NF saddle-field gun (Ion Tech Ltd, Teddington, UK) attached to the FAB source. The FAB matrix used was magic bullet (MB), which is a 3:1 mixture of dithiothreitol and dithioerythritol. Glycerol, the most commoniy 
used FAB matrix, was not used owing to the poor solubility and low sensitivity of the cyclic acetals in this matrix. Approximately $2 \mu \mathrm{L}$ of the MB matrix was spread onto the brass tip of a direct insertion probe, and the sample was then dissolved into the matrix (concentration $\sim 0.1 \mathrm{M}$ ). 'Lo study concentration effects, a series of FAB experiments were also performed using only the pure cyclic acetals with no supporting matrix because these compounds are themselves viscous liquids. Three separate FAB experiments were performed for each cyclic acetal under both sets of conditions, with data being collected for at least the first 2 min of bombardment.

A VG Trio-1 quadrupole mass spectrometer was used to acquire the $\mathrm{CI}$ and $\mathrm{EI}(70 \mathrm{eV})$ mass spectra. The ion source temperature was kept at $200{ }^{\circ} \mathrm{C}$ for these experiments. The pressures of the $\mathrm{CI}$ reagent gases [methane $\left(\mathrm{CH}_{4}\right)$, isobutane $\left(i-\mathrm{C}_{4} \mathrm{H}_{10}\right)$, and ammonia $\left(\mathrm{NH}_{3}\right)$, were adjusted to optimize the protonation of methyl stearate. The quadrupole instrument was used for these experiments because the EI/CI source in the sector instrument did not maintain sufficient pressure for good-quality CI data.

Metastable ion data were obtained by mass-analyzed ion kinetic energy spectrometry (MIKES) using the Kratos MS50TC mass spectrometer. For MIKES analysis, the second electrostatic sector was scanned while the first was maintained at its normal value. Helium was used as the collision gas in the third field-free region for the collision-activated dissociation (CAD) experiments. The pressure of helium was set to reduce the precursor ion intensity by $50 \%$.

\section{Results and Discussion}

Structures 1-8 show the structures of the 2-phenyl1,3-dioxolanes used in this study.

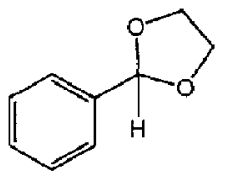

1<smiles>[R]C1COC(c2ccccc2)O1</smiles>

3: $R=C_{4} H_{9}$

5: $\mathrm{R}=\mathrm{C}_{6} \mathrm{H}_{13}$

7: $\mathrm{A}=\mathrm{G}_{10} \mathrm{H}_{21}$

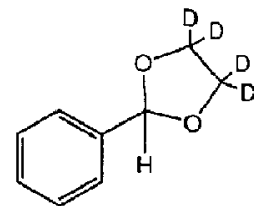

2

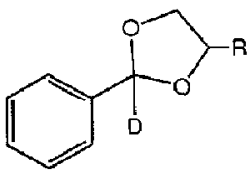

4: $\mathrm{R}=\mathrm{C}_{4} \mathrm{H}_{9}$

6: $\mathrm{R}=\mathrm{C}_{6} \mathrm{H}_{13}$

8: $\mathrm{R}=\mathrm{C}_{10} \mathrm{H}_{21}$
First, we discuss the data obtained for the cyclic acetals using the gas-phase ionization techniques. The relative intensities of the molecular ion species generated by $\mathrm{EI}(70 \mathrm{eV})$ and $\mathrm{CI}\left(\mathrm{NH}_{3}, i-\mathrm{C}_{4} \mathrm{H}_{10}, \mathrm{CH}_{4}\right)$ are recorded in Table 1 . CI $\left(\mathrm{NH}_{3}\right)$ data were only collected for three of the cyclic acetals because these results amply demonstrated the domination of the $[\mathrm{M}+\mathrm{H}]^{+}$ molecular ion under these conditions [34]. The precision of the results obtained on the quadrupole instrument was tested under $\mathrm{CI}\left(i-\mathrm{C}_{4} \mathrm{H}_{10}\right)$ conditions. Three separate measurements were taken for all of the cyclic acetals, with each measurement performed on different days. The average $\mathrm{CI}\left(i-\mathrm{C}_{4} \mathrm{H}_{10}\right)$ relative intensities shown in Table 1 were found to have a precision of less than $\pm 5 \%$ (absolute standard deviation). Representative EI and CI mass spectra for 4-butyl-2-phenyl1,3-dioxolane (3) and its deuterated analngue (4) are displayed in Figures 1 and 2.

Summarizing the EI $(70 \mathrm{eV})$ data for the nondeuterated cyclic acetals, the $[\mathrm{M}-\mathrm{H}]^{+}$peak is dominant in the molecular ion region, with a moderate $\mathrm{M}^{-+}$also present (Table 1; Figure 1a). The presence of intense $[\mathrm{M}-\mathrm{H}]^{+}$peaks in EI for various cyclic 1,3-dioxolanes has been previously noted [40-43]. A reaction pathway where $[\mathrm{M}-\mathrm{H}]^{+}$formation occurs through loss of $\mathrm{H}^{\text {. }}$ from $\mathrm{M}^{+}{ }^{+}$was verified in this work by a unimolecular MIKES experiment. For 2-phenyl-1,3-dioxolane-4,5- $d_{4}$ (2), loss of $\mathrm{H}^{\prime}$ from the 2-position is preferred to loss of $D^{*}$ (Table 1) because of the isolope effect and the considerable resonance stabilization of the resultant cation provided by the oxygen atoms and the phenyl ring. It is assumed that loss of $2-\mathrm{H}^{\circ}$ is also favored for the nondeuterated 4-alkyl-2-phenyl-1,3-dioxolanes $(3,5,7)$ as a result of the charge stabilization effect. Interestingly, however, for the 4-alkyl-2-phenyl-1,3-dioxolane-2- $d$ acetals $(4,6,8), \mathrm{H}^{\circ}$ loss is favored over loss of $\mathrm{D}^{-}$from the 2-position (Table 1; Figure $1 \mathrm{~b}$ ). This is probably due to the primary kinetic isotope effect, where the rate of decomposition of the $C-D$ bond is slower than that of the $\mathrm{C}-\mathrm{H}$ bond [44]. On varying the electron energy from $70 \mathrm{eV}$ down to $10 \mathrm{eV}$ for 4-butyl-2-phenyl-1,3-dioxolane-2-d (4), the relative intensity of the $[\mathrm{M}-\mathrm{D}]^{+}$species was seen to decrease with respect to $[\mathrm{M}-\mathrm{H}]^{+}$, which is consistent with an isotope effect. The loss of $\mathrm{H}^{-}$possibly occurs at the 4-position, where resonance stabilization of the cation is provided by a single oxygen as well as an anticipated inductive stabilizing effect by the alkyl chain. It cannot be ruled out that loss of $4-\mathrm{H}^{\circ}$ from $\mathrm{M}^{++}$also contributes to the $[\mathrm{M}-\mathrm{H}]^{+}$peak intensity for the nondeuterated acetals. Also characteristic of the EI mass spectra for the cyclic acetals is a fragment of strong intensity at $m / z 105$ (Figure 1). This fragment originates from the $[\mathrm{M}-\mathrm{H}]^{+}$species for the nondeuterated 1,3-dioxolanes, with cleavage of the fivemembered ring and loss of $-\mathrm{C}_{2} \mathrm{H}_{3} \mathrm{RO}$ as shown in Scheme I [40,43]. The invariance of the fragment mass on deuterium labeling (Figure 1) supports the proposed identity of this fragment.

From the $\mathrm{CI}\left(\mathrm{NH}_{3}, i-\mathrm{C}_{4} \mathrm{H}_{10}, \mathrm{CH}_{4}\right)$ mass spectra for 
Table 1. Relative intensity (\%) of peaks in the molecular ion region of the electron ionization and chemical ionization $\left(\mathrm{NH}_{3}, i-\mathrm{C}_{4} \mathrm{H}_{10}, \mathrm{CH}_{4}\right)$ mass spectra corrected for isotopic contributions

\begin{tabular}{|c|c|c|c|c|c|}
\hline \multirow[b]{2}{*}{ Structure } & \multirow{2}{*}{$\begin{array}{l}\text { Molecular } \\
\text { ion }\end{array}$} & \multirow{2}{*}{$\begin{array}{c}\text { Electron } \\
\text { ionization } \\
(70 \mathrm{eV})\end{array}$} & \multicolumn{3}{|c|}{ Chemical ionization } \\
\hline & & & $\mathrm{NH}_{3}$ & $j-\mathrm{C}_{4} \mathrm{H}_{10}$ & $\mathrm{CH}_{4}$ \\
\hline \multirow[t]{3}{*}{1} & {$[\mathrm{M}+\mathrm{H}]^{+}$} & - & 100 & 100 & 100 \\
\hline & $\mathbf{M}^{+}$ & 17 & 2 & 6 & 12 \\
\hline & {$[M-H]^{+}$} & 100 & 7 & 14 & 69 \\
\hline \multirow[t]{4}{*}{2} & {$\left[\mathrm{M}+\mathrm{H}^{+}\right.$} & - & 100 & 100 & 100 \\
\hline & $M^{++}$ & 18 & 5 & 9 & 12 \\
\hline & {$[M-H]^{+}$} & 100 & 8 & 12 & 58 \\
\hline & {$[M-D]^{+}$} & 2 & - & - & - \\
\hline \multirow[t]{3}{*}{3} & {$[\mathrm{M}+\mathrm{H}]^{+}$} & - & - & 100 & 100 \\
\hline & $M^{++}$ & 20 & - & 5 & 14 \\
\hline & $[\mathrm{M}-\mathrm{H}]]^{]}$ & 100 & - & 22 & 90 \\
\hline \multirow[t]{4}{*}{4} & {$[\mathrm{M}+\mathrm{H}]^{+}$} & - & - & 100 & 100 \\
\hline & $M^{++}$ & 28 & - & 7 & 18 \\
\hline & {$[\mathrm{M}-\mathrm{H}]^{+}$} & 100 & - & 16 & 48 \\
\hline & {$[M-D]^{+}$} & 37 & - & 13 & 30 \\
\hline \multirow[t]{3}{*}{5} & {$[\mathrm{M}+\mathrm{H}]^{+}$} & - & 100 & 100 & 100 \\
\hline & $M^{++}$ & 21 & 3 & 7 & 16 \\
\hline & {$[M-H]^{+}$} & 100 & 10 & 29 & 96 \\
\hline \multirow[t]{4}{*}{6} & {$[\mathrm{M}+\mathrm{H}]^{+}$} & - & - & 100 & 100 \\
\hline & $M^{++}$ & 31 & - & 7 & 15 \\
\hline & {$[\mathrm{M}-\mathrm{H}]^{+}$} & 100 & - & 10 & 33 \\
\hline & {$[M-D]^{+}$} & 47 & - & 7 & 23 \\
\hline \multirow[t]{3}{*}{7} & {$[\mathrm{M}+\mathrm{H}]^{+}$} & - & - & 100 & 100 \\
\hline & $\mathbf{M}^{++}$ & 14 & - & 6 & 15 \\
\hline & {$[M-H]^{+}$} & 100 & - & 23 & 78 \\
\hline \multirow[t]{4}{*}{8} & {$[\mathrm{M}+\mathrm{H}]^{+}$} & - & - & 100 & 100 \\
\hline & $M^{++}$ & 29 & - & 6 & 19 \\
\hline & {$[M-H]^{+}$} & 100 & - & 9 & 47 \\
\hline & {$[M-D]^{+}$} & 57 & - & 8 & 24 \\
\hline
\end{tabular}

the cyclic acetals, $[\mathrm{M}+\mathrm{H}]^{+}$is observed to be the most intense molecular ion species (Table 1; Figure 2). The $[\mathrm{M}+\mathrm{H}]^{+}$species was also dominant in a previous $\mathrm{CI}$ $\left(i-\mathrm{C}_{4} \mathrm{H}_{10}\right)$ study of 2-ethenyl-4-methyl-1,3-dioxolane, with no other ions of significant intensity present in the molecular ion region [41]. Formation of $[\mathrm{M}-\mathrm{H}]^{+}$ for the cyclic acetals on hydride abstraction in CI becomes more important as the reagent gas changes from $\mathrm{NH}_{3}$ to $i-\mathrm{C}_{4} \mathrm{H}_{10}$ to $\mathrm{CH}_{4}$ (Table 1; Figure 2). This is consistent with the increasing hydride ion affinities (HIAs) of the respective protonated reactant gas species, shown in Table 2. In CI $\left(\mathrm{CH}_{4}\right)$, formation of $[\mathrm{M}+\mathrm{H}]^{+}$and $[\mathrm{M}-\mathrm{H}]^{+}$can be discussed in terms of competitive gas-phase ion-molecule reactions involving the neutral acetals, whereas in $\mathrm{CI}\left(\mathrm{NH}_{3}, i-\mathrm{C}_{4} \mathrm{H}_{10}\right)$,
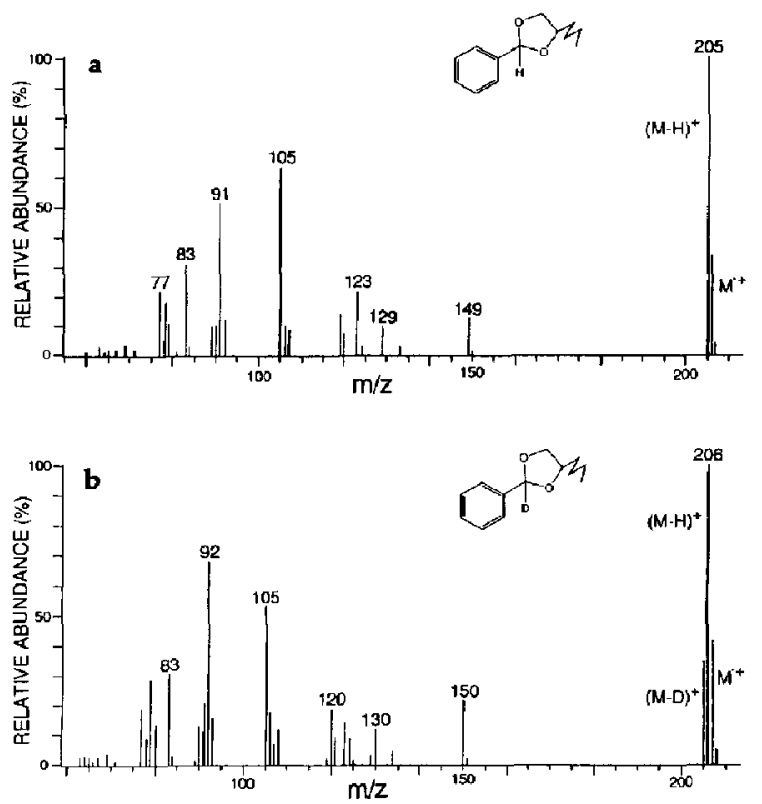

Figure 1. EI $(70 \mathrm{eV})$ mass spectrum of (a) 4-butyl-2-phenyl-1,3dioxolane (3) and (b) 4-butyl-2-phenyl-1,3-dioxolane-2-d (4); EI ion source temperature $200^{\circ} \mathrm{C}$.
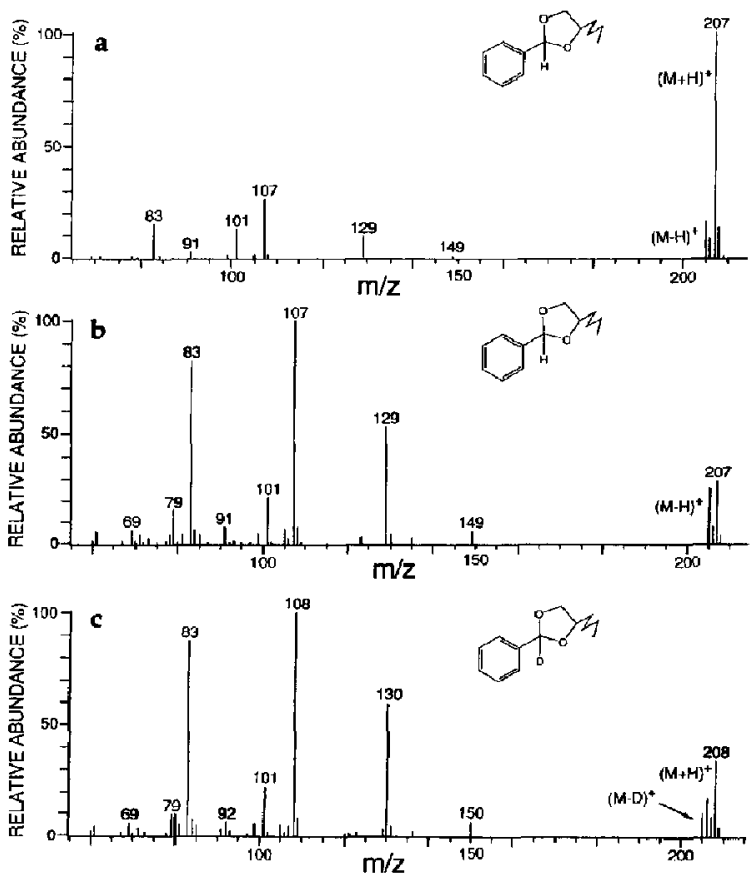

Figure 2. (a) $\mathrm{CI}\left(i-\mathrm{C}_{4} \mathrm{H}_{10}\right)$ mass spectrum of 4-butyl-2-phenyl1,3-dioxolane (3); (b) $\mathrm{CI}\left(\mathrm{CH}_{4}\right)$ of 4-butyl-2-phenyl-1,3-dioxolane (3); and (c) $\mathrm{CI}\left(\mathrm{CH}_{4}\right)$ of 4-butyl-2-phenyl-1,3-dioxolane-2-d (4); $\mathrm{CI}$ ion source temperature $200^{\circ} \mathrm{C}$. 


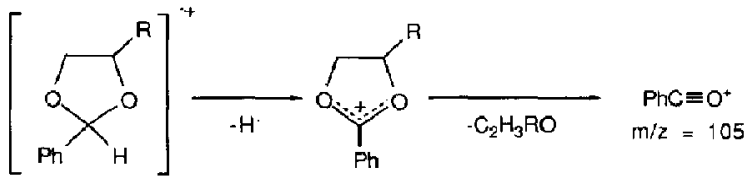

Scheme I

protonation is strongly favored over hydride abstraction (Table 1; ref 34). Formation of $\left[\mathrm{M}-\mathrm{H}^{+}\right.$on hydride abstraction in $\mathrm{CI}\left(\mathrm{CH}_{4}\right)$ has been reported for many classes of molecules [45]. CAD/MTKES experiments were performed to verify that the $[\mathrm{M}+\mathrm{H}]^{+}$ ions generated in $\mathrm{CI}\left(\mathrm{CH}_{4}\right)$ were not the precursors of $[\mathrm{M}-\mathrm{H}]^{+}$. Another possible contribution to the increased $[\mathrm{M}-\mathrm{H}]^{+}$intensity for $\mathrm{CI}\left(\mathrm{CH}_{4}\right)$ is the gasphase decomposition of $\mathrm{M}^{++}$to $[\mathrm{M}-\mathrm{H}]^{+}$, analogous to that occurring in EI. The formation of $\mathrm{M}^{++}$in CI for the cyclic acetals is only potentially significant when methane is the reagent gas. This is because the recombination energies for $\mathrm{CH}_{5}^{+}$and $\mathrm{C}_{2} \mathrm{H}_{5}^{+}$(Table 2) may be greater than those for the cyclic acetals and, hence, charge transfer from the cyclic acetals may accur. Table 1 shows that the relative intensity of $\mathrm{M}^{+}$is only significant $(>10 \%)$ in $\mathrm{CI}\left(\mathrm{CH}_{4}\right)$. In $\mathrm{CI}\left(\mathrm{CH}_{4}\right)$ for the 2-d acetals, $\mathrm{H}^{-}$abstraction is slightly favored over loss of $\mathrm{D}^{-}$from the 2-position (Table 1; Figure 2c). This is assumed to be a consequence of the primary kinetic isotope effect involved in the fragmentation.

The extent of fragmentation observed in $\mathrm{CI}$ for the cyclic acetals corresponds to the exothermicity of proton transfer between the protonated reactant gas species and the cyclic acetal. The proton affinities of the reactant gas species are shown in Table 2. Consequently, the extent of fragmentation follows the order $\mathrm{CI}\left(\mathrm{CH}_{4}\right)>\mathrm{CI}\left(i-\mathrm{C}_{4} \mathrm{H}_{10}\right)>\mathrm{CI}\left(\mathrm{NH}_{3}\right)$ (see Figure 2 and Paul et al. [34]). Because virtually no fragmentation is observed for the compounds in $\mathrm{CI}\left(\mathrm{NH}_{3}\right)$ [34], it can be predicted that the cyclic acetals have a proton affinity similar to that of $\mathrm{NH}_{3}(205 \mathrm{kcal} / \mathrm{mol}$, Table 2). The most prominent fragment observed in the CI mass spectra is at $m / z 107$ for the nondeuterated acetals and at $m / z 108$ for the deuterated analogues (Figure 2). From unimolecular and CAD/MIKES, it is determined that $[\mathrm{M}+\mathrm{H}]^{+}$is a precursor to these species, and the anticipated reaction pathway is shown in Scheme II. The shift of fragment mass for the deuterated cyclic acetals supports Scheme II. Of note, fragment formation at $m / z$ 105, thought to originate from $[\mathrm{M}-\mathrm{H}]^{+}$, is small in $\mathrm{CI}\left(\mathrm{CH}_{4}\right)$, where the $[\mathrm{M}-\mathrm{H}]^{+}$ intensity is significant (Figure $2 \mathrm{~b}$ ). Hence, it is possible that increased decomposition of $[\mathrm{M}+\mathrm{H}]^{+}$with respect to $[\mathrm{M}-\mathrm{H}]^{+}$also contributes to the larger relative intensity of $[\mathrm{M}-\mathrm{H}]^{+}$observed in $\mathrm{CI}\left(\mathrm{CH}_{4}\right)$.

We now review $F A B$ data obtained for the cyclic acetals. Consistent FAB mass spectra could not be attained for the cyclic acetals 1 and 2 owing to the relatively high volatility of these compounds. For the other cyclic acetals, three separate FAB data sets were collected using an MB matrix [i.e., FAB (MB)]. The average relative intensities of the molecular ion species for each cyclic acetal in FAB (MB) are recorded in Table 3 . The quoted uncertainty corresponds to the absolute standard deviation of the mean value. Also present in Table 3 is the time dependence of the relative molecular ion intensities over the period of FAB. Representative FAB (MB) mass spectra for 4butyl-2-phenyl-1,3-dioxolane (3) and its deuterated analogue (4) are displayed in Figure 3.

From the FAB (MB) mass spectra of the nondeuterated acetals $(3,5,7)$, the $[\mathrm{M}-\mathrm{H}]^{+}$is the major species present in the molecular ion region (Table 3; Figure 3a). Dominant formation of anomalous $[\mathrm{M}-\mathrm{H}]^{+}$ molecular ions in FAB was previously reported for derivatized sugars [35] and compounds containing long alkyl chains [37]. Only a small decrease in the intensity of $[\mathrm{M}+\mathrm{H}]^{+}$with respect to $[\mathrm{M}-\mathrm{H}]^{+}$occurs over the time frame of the experiment (Table 3). In FAB (MB) for the 2-d acetals, two different types of time dependence are observed for the molecular ions (Table 3 ).

Table 2. Ion thermochemical data for reagent gases

\begin{tabular}{|c|c|c|c|c|}
\hline Reagent gas & $\begin{array}{l}\text { Reactant } \\
\text { ion }\left(\mathrm{RH}^{+}\right)\end{array}$ & $\begin{array}{c}\text { Proton affinity }(\mathrm{R})^{\mathrm{a}} \\
(\mathrm{kcal} / \mathrm{mol})\end{array}$ & $\begin{array}{l}\text { Hydride ion } \\
\text { affinity }\left(\mathrm{RH}^{+}\right)^{\mathrm{b}} \\
\text { (kcal/mol) }\end{array}$ & $\begin{array}{c}\text { Recombination } \\
\text { energy }\left(\mathrm{RH}^{+}\right)^{\mathbf{c}} \\
(\mathrm{eV})\end{array}$ \\
\hline \multirow[t]{2}{*}{$\mathrm{CH}_{4}^{\mathrm{d}}$} & $\overline{\mathrm{CH}}$ & 130.5 & 270 & 8.0 \\
\hline & $\mathrm{C}_{2} \mathrm{H}_{5}^{+}$ & 163.5 & 272 & 8.4 \\
\hline$i-\mathrm{C}_{4} \mathrm{H}_{10}^{\mathrm{d}}$ & $\mathrm{C}_{4} \mathrm{H}_{\mathrm{g}}^{+}$ & 196.9 & 231 & 6.9 \\
\hline $\mathbf{N H}_{3}^{\mathrm{d}}$ & $\mathrm{NH}_{4}^{+}$ & 205.0 & 195 & 4.8 \\
\hline Glycorol (Gly) & Gly $\cdot H^{+}$ & $209^{e}$ & $191^{f}$ & - \\
\hline Magic bullet (MB) & $\mathrm{MB} \cdot \mathrm{H}^{+}$ & $209^{9}$ & $191^{9}$ & - \\
\hline
\end{tabular}

${ }^{a}$ Proton affinity (R) for reaction $\mathrm{RH}^{+}=\mathrm{R}+\mathrm{H}^{+}$.

bydride ion affinity $\left(\mathrm{RH}^{+}\right)$for reaction $\mathrm{RH}_{2}$ (or $\left.\mathrm{R}+\mathrm{H}_{2}\right)=\mathrm{RH}^{+}+\mathrm{H}$

Recombination energy $\left(\mathrm{RH}^{\dagger}\right)$ for reaction $\mathrm{RH}=\mathrm{RH}^{+}+e$ :

All data from Harrison [45].

eProton affinity (Gly) from Sunner et al. [13].

${ }^{f} \mathrm{Hydride}$ ion affinity $\left(\mathrm{Gly} \cdot \mathrm{H}^{+}\right.$) calculated using proton affinity $(\mathrm{G} / \mathrm{y})$.

${ }^{8}$ Hydride ion affinity (MB $\mathrm{H}^{+}$) and proton atfinity (MB) assumed equal to corresponding glyceral data. 


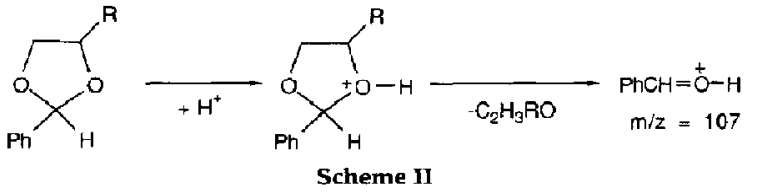

For 4-butyl-2-phenyl-1,3-dioxolane-2-d (4) and 4-hexyl2-phenyl-1,3-dioxolane-2- $d(6)$, the $[\mathrm{M}+\mathrm{H}]^{+}$is initially more intense than $[\mathrm{M}-\mathrm{D}]^{+}$, which is formed in preference to $[\mathrm{M}-\mathrm{H}]^{+}$. With time, the relative intensity of $[M-D]^{+}$increases with respect to $[M+H]^{+}$, and by the end of the data accumulation this species is dominant (Table 3). The absolute intensities of molecular ion species generated in FAB for 4-butyl-2-phenyl1,3-dioxolane-2-d (4) are shown in Figure 4. Although the absolute intensities of both $[\mathrm{M}+\mathrm{H}]^{+}$and $[\mathrm{M}-$ $\mathrm{D}^{+}$decrease with time, the $[\mathrm{M}+\mathrm{H}]^{+}$intensity does so at a faster rate compared with $\left[\mathrm{M}-\mathrm{D}^{+}\right.$. This leads to the time dependences observed in Table 3 for compounds 4 and 6 . In contrast, for 4-decyl-2-phenyl-1,3dioxolane-2- $d(8)$, the $[\mathrm{M}-\mathrm{D}]^{+}$is the major molecular ion species for the duration of the experiment (Table 3). The general observation of increased $[\mathrm{M}+\mathrm{H}]^{+}$ intensities in FAB (MB) for the 2-d acetals with respect to the 2-I acetals is probably a consequence of the primary kinetic isotope effect (see below). The low intensity of $[\mathrm{M}-\mathrm{H}]^{+}$relative to $[\mathrm{M}-\mathrm{D}]^{+}$in the $2-\mathrm{d}$ acetal experiments shows that deuterium loss from the 2-position is favored where considerable resonance stabilization of the resultant cation is possible. Obviously, in the absence of an isotope effect, the loss of hydrogen from the 2-position of nondeuterated acetals is expected for $[\mathrm{M}-\mathrm{H}]^{+}$formation in $\mathrm{FAB}(\mathrm{MB})$. Baldwin et al. [37] also performed deuterium-labeling experiments to gain stereochemical information on $[\mathrm{M}-\mathrm{H}]^{+}$ formation in FAB. In contrast to our results, they came to the conclusion that for a long ether-containing alkyl chain, hydrogen loss occurs from the alkyl group as opposed to the $\alpha$-position of the oxygen. This result, however, is by no means conclusive because only one of the $\alpha$-methylene groups to the ether oxygen was labeled [37].

The average relative intensities of the molecular ion species generated in FAB for the pure cyclic acetals with no supporting matrix are also shown in Table 3. No significant time dependence of the relative molecular ion intensities occurs over the duration of FAB. For the pure nondeuterated acetals, the relative intensities of the molecular ion species are similar to those in FAB with the MB matrix (Table 3). For the pure 2-d acetals, the significant time dependence seen in FAB (MB) for

Table 3. Relative intensity $(\%)$ of peaks in the molecular ion region of the fast-atom bombardment mass spectra corrected for isotopic contributions

\begin{tabular}{|c|c|c|c|c|c|}
\hline \multirow[b]{2}{*}{ Structure } & \multirow{2}{*}{$\begin{array}{c}\text { Molecular } \\
\text { iun }\end{array}$} & \multicolumn{3}{|c|}{ Acetal/magic bullet } & \multirow{2}{*}{$\begin{array}{l}\text { Pure acetal } \\
\text { (0-2 min) }\end{array}$} \\
\hline & & $0-30 \mathrm{~s}$ & $\sim 1$ Inin & $\sim 2$ min & \\
\hline \multirow[t]{3}{*}{3} & {$[\mathrm{M}+\mathrm{H}]^{+}$} & $25 \pm 11$ & $18 \pm 8$ & $11 \pm 4$ & $31 \pm 7$ \\
\hline & $\mathbf{M}^{++}$ & $2 \pm 1$ & $1 \pm 1$ & $1 \pm 1$ & $16 \pm 2$ \\
\hline & {$[\mathrm{M}-\mathrm{H}]^{+}$} & 100 & 100 & 100 & 100 \\
\hline \multirow[t]{4}{*}{4} & {$\left[\mathbf{M}+\mathrm{H}^{+}\right.$} & 100 & $75 \pm 7$ & $27 \pm 7$ & $31 \pm 13$ \\
\hline & $M^{+}+$ & $4 \pm 2$ & $3 \pm 2$ & $3 \pm 1$ & $11 \pm 4$ \\
\hline & {$[\mathrm{M}-\mathrm{H}]^{+}$} & $9 \pm 3$ & $6 \pm 1$ & $4 \pm 1$ & $35 \pm 11$ \\
\hline & {$[M-D]^{+}$} & $68 \pm 5$ & 100 & 100 & 100 \\
\hline \multirow[t]{3}{*}{5} & $\mathbf{I M}+\mathbf{H I}^{+}$ & $32 \pm 13$ & $27 \pm 8$ & $19 \pm 5$ & $34 \pm 4$ \\
\hline & $\mathbf{M}^{++}$ & $7 \pm 3$ & $3 \pm 1$ & $1 \pm 1$ & $16 \pm 3$ \\
\hline & {$[\mathrm{M}-\mathrm{H}]^{+}$} & 100 & 100 & 100 & 100 \\
\hline \multirow[t]{4}{*}{6} & {$\left[\mathrm{M}+\mathrm{H}^{+}\right.$} & 100 & $87 \pm 12$ & $53 \pm 6$ & $60 \pm 10$ \\
\hline & $M^{\cdot 1}$ & $3 \pm 1$ & $4 \pm 1$ & $2 \pm 1$ & $10 \pm 1$ \\
\hline & {$[M-H]^{+}$} & $11 \pm 2$ & $a \pm 1$ & $9 \pm 3$ & $51 \pm 5$ \\
\hline & {$[M-D]^{+}$} & $82 \pm 12$ & 100 & 100 & 100 \\
\hline \multirow[t]{3}{*}{7} & {$\left[\mathrm{M}+\mathrm{H}^{+}\right.$} & $22 \pm 8$ & $19 \pm 6$ & $18 \pm 5$ & $38 \pm 5$ \\
\hline & $\mathbf{M}^{++}$ & $3 \pm 2$ & $2 \pm 1$ & $3 \pm 1$ & $8 \pm 4$ \\
\hline & {$[\mathrm{M}-\mathrm{H}]^{+}$} & 100 & 100 & 100 & 100 \\
\hline \multirow[t]{4}{*}{8} & {$[\mathbf{M}+\mathbf{H}]^{+}$} & $57 \pm 12$ & $65 \pm 13$ & $57 \pm 12$ & $42 \pm 3$ \\
\hline & $M^{++}$ & $4 \pm 2$ & $4 \pm 3$ & $5 \pm 1$ & $8 \pm 1$ \\
\hline & {$[\mathrm{M}-\mathrm{H}]^{+}$} & $20 \pm 4$ & $18 \pm 5$ & $12 \pm 1$ & $41 \pm 3$ \\
\hline & {$[M-D]^{+}$} & 100 & 100 & 100 & 100 \\
\hline
\end{tabular}



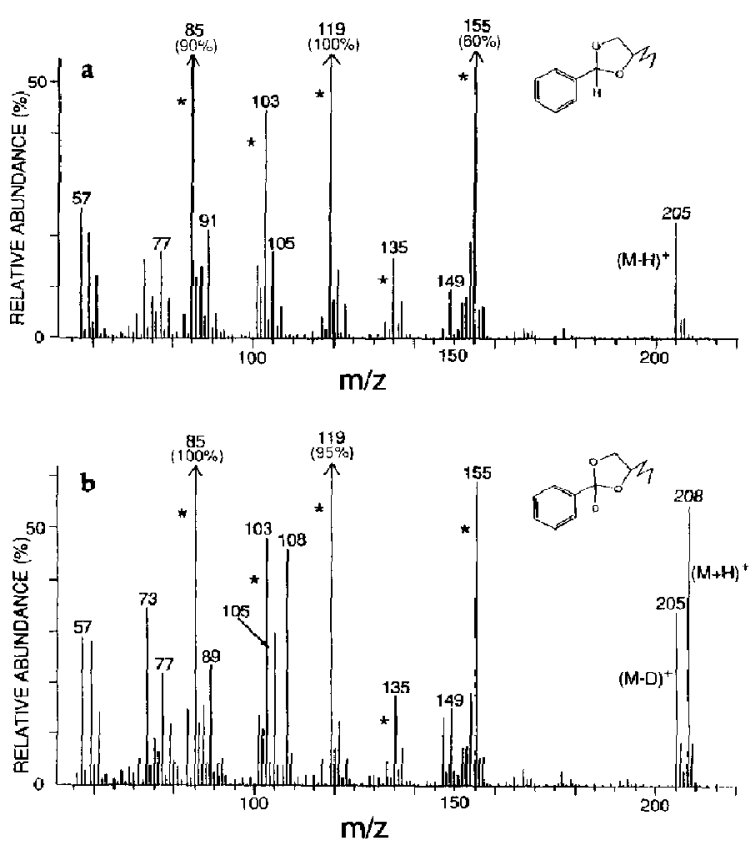

Figure 3. FAB mass spectrum of (a) 4-butyl-2-phenyl-1,3-dioxolane (3) and (b) 4-butyl-2-phenyl-1,3-dioxolane-2-d (1); FAB matrix is $\mathrm{MB}_{;}^{*}$, matrix peaks; spectra collected after $\sim 15 \mathrm{~s}$ of FAB

compounds 4 and 6 is absent (Table 3 ). The $[\mathrm{M}+\mathrm{H}]^{+}$ and $[M-D]^{+}$intensities obtained for the pure $2-d$ acetals are similar to those at the end of the FAB (MB) experiments (Table 3 ). The $\mathrm{M}^{+}$peak in FAB of pure acetals, although small, is more significant than in FAB

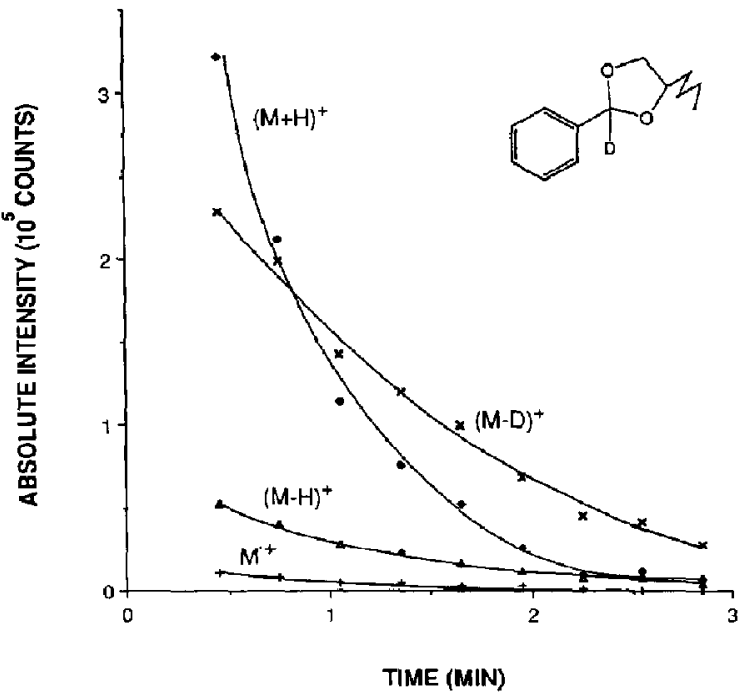

Figure 4. Time dependence of the absolute molecular ion intensities obtained in FAB for 4-butyl-2-phenyl-1,3-dioxolane-2-d (4) with $\mathrm{MB}$ as the liquid matrix.
(MB), where the $\mathrm{M}^{++}$intensity is negligible (Table 3). The formation of $\mathrm{M}^{++}$is probably due to EI-type processes in the gas phase that are a consequence of the volatility of the pure liquid acetals. Formation of $\mathrm{M}^{+}$on FAB of gases has been reported [46, 47], and Renner and Spiteller [48] have obtained EI-like spectra for volatile organics in FAB without a supporting liquid matrix. The increased $[\mathrm{M}-\mathrm{H}]^{+}$intensity for the pure 2-d acetals compared with those dissolved in the MB matrix (Table 3) is probably a consequence of $\mathbf{M}^{++}$ formation followed by loss of $\mathrm{H}^{\circ}$ in a manner analogous to that previously described for EI. These gas-phase EI-type processes, however, should not dramatically affect the relative $[\mathrm{M}+\mathrm{H}]^{+}$and $[\mathrm{M}-\mathrm{D}]^{+}$ intensities in FAB for the pure 2-d acetals.

A major pathway of fragmentation in $\mathrm{FAB}(\mathrm{MB})$ involves the species at $m / z \quad 105$ and $107 / 108$ (Figure 3), analogous to those fragments observed in $\mathrm{EI}$ and $\mathrm{CI}$ (Figures 1 and 2). These fragments were proved by unimolecular and CAD/MIKES experiments to originate from $[\mathrm{M}-\mathrm{H} / \mathrm{D}]^{+}$and $[\mathrm{M}+\mathrm{H}]^{+}$, respectively (Schemes I and II). In FAB (MB) for the nondeuterated acetals, the fragment at $m / z 105$ is most important relative to that at $m / z 107$ (Figure $3 \mathrm{a}$ ), reflecting the domination of the $[\mathrm{M}-\mathrm{H}]^{+}$molecular ion. For the $2-\mathrm{d}$ acetals, the increased presence of $[\mathrm{M}+\mathrm{H}]^{+}$with respect to the 2- $\mathrm{H}$ acetals is reflected by the intensity of the fragment at $m / z 108$ (Figure $3 \mathrm{~b}$ ). Formation of both CI-like and EI-like fragments in F $\Lambda$ B for prenylated flavonoids has been reported by Takayama et al. $[30,33]$.

We now examine the extent to which El-like processes may contribute to the $\mathrm{FAB}$ mass spectra for the cyclic acetals. For both FAB (MB) and EI of the nondeuterated cyclic acetals, a dominant $[\mathrm{M}-\mathrm{H}]^{+}$molecular ion exists (Tables 1 and 3; Figures $1 \mathrm{a}$ and 3a). The presence of a fragment of significant intensity at $\mathrm{m} / \mathrm{z}$ 105 in EI (Scheme I) and FAB shows the formation of energetic $[\mathrm{M}-\mathrm{H}]^{+}$species in both techniques. Hard EI-like fragmentation in FAB has been previously discussed [30, 33]; however, the only known ionic precursor to $[\mathrm{M}-\mathrm{H}]^{+}$in $\mathrm{EI}, \mathrm{M}^{+}$, is of negligible intensity in FAB (MB). This suggests that the processes leading to $[\mathrm{M}-\mathrm{H}]^{+}$formation in $\mathrm{FAB}(\mathrm{MB})$ are different from those known in EI. In addition, for the 2-d acetals, $[\mathrm{M}-\mathrm{D}]^{+}$formation is favored over $[\mathrm{M}-\mathrm{H}]^{+}$in $\mathrm{FAB}$ (MB), whereas in EI, the $[\mathrm{M}-\mathrm{H}]^{+}$species is more intense. This again indicates that the molecular ion species are formed by different mechanisms in the respective techniques. Obviously, the presence of [M $+\mathrm{H}]^{+}$in FAB (MB) for the 2-d acetals cannot be rationalized in terms of gas-phase EI processes. As previously mentioned, EI-type processes may contribute to the relative intensities of some of the molecular ions in FAB of the pure cyclic acetals.

We next explore the possibility of the involvement of CI-like gas-phase ionization processes in FAB of the cyclic acetals. The formation of $[\mathrm{M}-\mathrm{H}]^{+}$for nondeuterated cyclic acetals in both FAB (MB) and CI 
$\left(\mathrm{CH}_{4}\right)$ suggests that gas-phase hydride abstraction from the neutral acetal is a possible mechanism for ionization in FAB. It must be remembered, however, that $[\mathrm{M}-\mathrm{H}]^{+}$formation for the nondeuterated cyclic acetals in FAB (MB) is dominant, whereas in $\mathrm{CI}\left(\mathrm{CH}_{4}\right)$, formation of $[\mathrm{M}-\mathrm{H}]^{+}$is only competitive with protonation (Tables 1 and 3; Figures $2 \mathrm{~b}$ and 3a). Gas-phase ion-molecule reactions have indeed been proposed to be responsible for anomalous [M $-\mathrm{H}]^{*}$ formation in FAB for crown ethers [32]. Despite the differences in experimental conditions for $\mathrm{CI}$ and $\mathrm{FAB}(\mathrm{MB})$, an attempt can be made to rationalize the $F A B$ results in terms of gas-phase ion-molecule reactions through the gas collision model $[13,14]$. Using this model, gasphase thermodynamic data obtained from $\mathrm{CI}$ experiments have been used to explain trends in FAB results $[13,14]$. In the gas collision model, the protonated matrix is proposed to be the major gas-phase reactant species. Hence, to compare FAB (MB) results for cyclic acetals with those obtained in $\mathrm{CI}$, a knowledge of the gas-phase HIA of protonated $\mathrm{MB}$ is required [34]. The closest comparable HIA value to that of protonated MB is for protonated glycerol (Gly) (Table 2). Although the HIA ( $\mathrm{Gly} \cdot \mathrm{H}^{+}$) value may not be quantitatively accurate for HIA $\left(\mathrm{MB} \cdot \mathrm{H}^{+}\right)$, HIA $\left(\mathrm{CH}_{5}^{+}\right)$is nearly 80 $\mathrm{kcal} / \mathrm{mol}$ greater than HIA $\left(\mathrm{Gly} \cdot \mathrm{H}^{+}\right)$, so that gasphase hydride abstraction, as observed in $\mathrm{CI}\left(\mathrm{CH}_{4}\right)$, would not be expected to prevail in FAB (MB) by the gas collision model. The reactive electrophilic species of the $\mathrm{CI}$ gas isobutane $\left(\mathrm{C}_{4} \mathrm{H}_{9}^{+}\right)$also has an HIA value $40 \mathrm{kcal} / \mathrm{mol}$ greater than that estimated for MB (Table 2 ), yet hydride abstraction is not competitive with protonation for cyclic acetals in the $\mathrm{CI}\left(i-\mathrm{C}_{4} \mathrm{H}_{10}\right)$ mass spectra (Table 1; ref 34). Hence, the presence of [M $\mathrm{H}]^{+}$as the major molecular ion in FAB (MB) for the 2-H acetals cannot be explained in terms of the gas collision model. A major difference in fragmentation patterns of $\mathrm{FAB}(\mathrm{MB})$ and $\mathrm{CI}\left(\mathrm{CH}_{4}\right)$ mass spectra is also observed for the nondeuterated cyclic acetals (Figures $2 \mathrm{~b}$ and $3 \mathrm{a})$. In $\mathrm{FAB}(\mathrm{MB})$, the major $\mathrm{CI}\left(\mathrm{CH}_{4}\right)$ fragments $(m / z 129,107,83$; Figure $2 b)$ are either weak or absent, whereas a peak of significant intensity at $m / z 105$ is only present in FAB (MB). The lack of significant CI-like fragments in FAB (MB) rules out the possibility of extensive gas-phase decomposition of $[\mathrm{M}+\mathrm{H}]^{+}$being responsible for the small $[\mathrm{M}+\mathrm{H}]^{+}$ signal for nondeuterated acetals (Table 3). Of interest, with respect to the gas-phase thermochemical data shown in Table 2, the estimated PA and HIA for MB and protonated $\mathrm{MB}$, respectively, closely resemble those for the $\mathrm{CI}$ reagent gas $\left(\mathrm{NH}_{3}\right)$. The lack of fragmentation in $\mathrm{CI}\left(\mathrm{NH}_{3}\right)$ [34] and the formation of a $[\mathrm{M}+\mathrm{H}]^{+}$parent molecular ion with no other significant molecular ions (Table 1; ref 34 ) again suggest that the ionization processes in CI and FAB for the cyclic acetals are not analogous. Further evidence is provided by the 2 -d acetals with $\mathrm{D}^{-}$loss favored in $\mathrm{FAB}$, whereas $\mathrm{H}^{-}$loss is preferred in CI (Tables 1 and 3; Figures 2c and $3 b$ ). In addition, there is no time dependence for the molecular ion intensities in $\mathrm{CI}$ for the 2-d acetals, whereas a strong effect is observed in $F A B$ for compounds 4 and 6 (Table 3; Figure 4). CAD/MIKES experiments showed that the $[\mathbf{M}-\mathbf{H}]^{+}$and $[\mathbf{M}-\mathrm{D}]^{+}$ ions produced in FAB for the cyclic acetals did not originate from gas-phase decomposition of $[\mathrm{M}+\mathrm{H}]^{+}$ [34]. This reaction pathway was also proved not to be an origin of $[\mathrm{M}-\mathrm{H}]^{+}$ions in FAB for crown ethers and fluorosugars $[32,36]$. In conclusion, the experimental evidence presented and the thermochemical data available indicate that $[\mathrm{M}-\mathrm{H} / \mathrm{D}]^{+}$ion formation in $F A B(M B)$ for the cyclic acetals and their deuterated analogues cannot be explained in terms of known gas-phase processes. Only undocumented ionization processes, such as the gas-phase protonation of FAB-desorbed $[\mathrm{M}-2 \mathrm{H}]$ species can be used to rationalize the FAB (MB) data for cyclic acetals in CI-like ionization terms. Even with this hypothesis, it would be difficult to explain the FAB results for the deuterated cyclic acetals, which require the protonation of the [M - HD] species.

An alternative interpretation of the FAB (MB) data for the cyclic acetals is that protonation and hydride abstraction occur in the condensed phase as competitive ion-molecule reactions. First, we attempt to explain the more straightforward $\mathrm{FAB}(\mathrm{MB})$ results for the nondeuterated cyclic acetals (Table 3 ) in terms of condensed-phase reactions. These reactions are shown below, where $\mathrm{M}$ represents the $2-\mathrm{H}$ acetals, and $\mathrm{R}_{x} \mathrm{H}^{+}$ and $\mathrm{R}_{y} \mathrm{H}^{+}$are the reactive ionic specie(s) for the respective reactions:

$$
\begin{aligned}
& \mathrm{M}_{\text {(soln) }}+\mathrm{R}_{x} \mathrm{H}_{\text {(soln) }}^{+}=\mathrm{MH}_{\text {(soln) }}^{+}+\mathrm{R}_{x(\text { soln })} \\
& \mathrm{M}_{\text {(soln) }}+\mathrm{R}_{y} \mathrm{H}_{\text {(soln) }}^{+}=[\mathrm{M}-\mathrm{H}]_{\text {(soln })}^{+}+\mathrm{R}_{y}\left(\mathrm{H}_{2}\right)_{(\text {soln })}
\end{aligned}
$$

The proposed gas-phase and condensed-phase potential energy diagrams describing protonation and hydride abstraction for the nondeuterated cyclic acetals are displayed in Figure 5. It is important to remind the reader that Figure 5 represents a qualitative interpretation of the situation due to the unknown nature of the

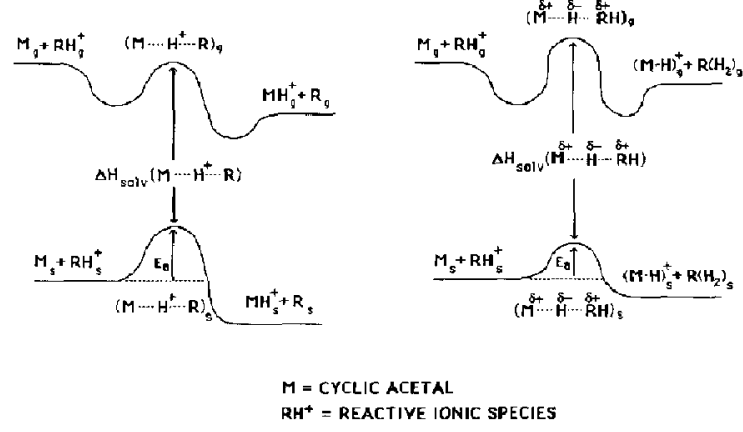

Figure 5. Proposed gas-phase and condensed-phase potential energy diagrams for protonation and hydride abstraction of the $2-\mathrm{H}$ cyclic acetals. 
reactive ionic specie(s) in the condensed-phase reactions. In the gas phase, $\left[\mathrm{M}+\mathrm{H}^{+}\right.$formation is favored for $\mathrm{CI}\left(\mathrm{NH}_{3}, i-\mathrm{C}_{4} \mathrm{H}_{10}\right)$, whereas in $\mathrm{CI}\left(\mathrm{CH}_{4}\right)$ competitive $[\mathrm{M}-\mathrm{H}]^{+}$formation takes place (Table 1 ; ref 34 ). Because the MB is assumed to have a proton affinity similar to ammonia (Table 2), its behavior as a reagent gas in $\mathrm{CI}$ for the cyclic acetals would be anticipated to be the same as that for ammonia (i.e., predominant $[\mathrm{M}+\mathbf{H}]^{+}$formation would occur). In the condensed phase, the activation energy barriers to the formation of $[\mathrm{M}+\mathrm{H}]^{+}$and $[\mathrm{M}-\mathrm{H}]^{+}$are known to be related to the solvation energies of the appropriate transition states for each reaction [49]. If a multicharge center transition state is present in the hydride abstraction reaction, this transition state would be better solvated than the corresponding proton transfer transition state, potentially leading to a lower activation energy barrier for $[\mathrm{M}-\mathrm{H}]^{+}$formation with respect to $[\mathrm{M}+\mathrm{H}]^{+}$, as shown in Figure 5. Only if the protonated MB is assumed to be the major reactive species for both protonation and hydride abstraction in the condensed phase and the gas phase $\left(\mathrm{RH}_{\mathrm{g}, \mathrm{s}}^{+}=\mathrm{MB} \cdot \mathrm{H}^{+}\right.$; Figure 5) does the situation depicted in Figure 5 take on a more quantitative meaning. In terms of the reaction rate expressions for reactions 1 and 2, shown below, where $k_{1}$ and $k_{2}$ are the rate constants, the solvation effect may lead to $k_{2} \gg k_{1}$ and, consequently, predominant $[\mathrm{M}-\mathrm{H}]^{+}$formation, as is observed in FAB for the nondeuterated cyclic acetals:

$$
\begin{aligned}
& d\left([\mathrm{M}+\mathrm{H}]^{+}\right) / d t=k_{1}[\mathrm{M}]\left[\mathrm{R}_{x} \mathrm{H}^{+}\right] \\
& d\left([\mathrm{M}-\mathrm{H}]^{+}\right) / d t=k_{2}[\mathrm{M}]\left[\mathrm{R}_{y} \mathrm{H}^{+}\right]
\end{aligned}
$$

This condensed-phase ionization model therefore provides a potential explanation for the domination of $[\mathbf{M}-\mathbf{H}]^{+}$in FAB for nondeuterated acetals, which, as previously discussed, could not be rationalized by the gas collision model. Hydride abstraction in the condensed phase has also been proposed to be the mechanism by which $[\mathrm{M}-\mathrm{H}]^{+}$formation occurs for fluorosugars in FAB [36].

We now attempt to fit the condensed-phase ionization model to the FAB (MB) results for deuterated acetals (Table 3 ). The anticipated condensed-phase reaction and rate expression for $\mathrm{D}^{-}$abstraction are as follows:

$$
\begin{aligned}
\mathrm{M}_{(\text {soln })}+\mathrm{R}_{y} \mathrm{H}_{\text {(soln) }}^{+} & =[\mathrm{M}-\mathrm{D}]_{(\text {soln })}^{+}+\mathrm{R}_{y}(\mathrm{HD})_{(\text {soln })} \\
d\left([\mathrm{M}-\mathrm{D}]^{+}\right) / d t & =k_{3}[\mathrm{M}]\left[\mathrm{R}_{y} \mathrm{H}^{+}\right]
\end{aligned}
$$

The reactant electrophilic species for reaction 3 are assumed to be the same as those for reaction 2 . For 4-butyl-2-phenyl-1,3-dioxolane-2-d (4) and 4-hexyl-2phenyl-1,3-dioxolane-2- $d(6)$, the $[\mathrm{M}+\mathrm{H}]^{+}$species is observed to be of similar intensity relative to that of
$[M-D]^{+}$during the first minute of FAB (Table 3). This is in contrast to the domination of $[\mathrm{M}-\mathrm{H}]^{+}$seen for the 2-H acetals (Table 3 ). This occurrence can be explained in terms of a smaller rate constant $k_{3}$ for $[\mathrm{M}-\mathrm{D}]^{+}$formation in the condensed phase (reaction 3a) with respect to $k_{2}$ for $[\mathrm{M}-\mathrm{H}]^{+}$formation (reaction 2a), which is a consequence of the kinetic isotope effect. Thus, the FAB (MB) data obtained for compounds 4 and 6 suggest that the formation of $[M-D]^{+}$ and $[\mathrm{M}+\mathrm{H}]^{+}$is competitive in the condensed phase $\left(k_{3} \approx k_{1}\right)$, accounting for the significant intensity of both species in the initial stages of the FAB experiment. Isotope effects also appear to influence the EI and $\mathrm{CI}$ data for the cyclic acetals (Table 1), although the mechanistic aspects of ionization in these techniques seem complex, and the isotope effect probably only partially accounts for the observed trends. It should be remembered for the 2-d acetals that in the gas phase, the loss of $D$ is less significant than the loss of $\mathrm{H}$ (Figures $\mathrm{lb}$ and $2 \mathrm{c}$ ), whereas in $\mathrm{FAB}$ loss of $\mathrm{D}$ dominates (Figure $3 \mathrm{~b}$ ). This reinforces the hypothesis that there is a lowering of the activation energy for the loss of $D$ in the condensed phase, as previously proposed. An additional facet of the FAB data for compounds 4 and 6 is the dramatic time dependence of the relative $[M-D]^{+}$and $[M+H]^{+}$intensities, illustrated in Figure 4. A much smaller variation in relative $[\mathrm{M}-\mathrm{H}]^{+}$and $[\mathrm{M}+\mathrm{H}]^{+}$intensities is observed for the nondeuterated acetals (Table 3 ). A tentative interpretation of this effect is a greater buildup in solution with time of those reactant electrophilic species responsible for $\mathrm{D}^{-}$abstraction $\left(\mathrm{R}_{y} \mathrm{H}^{+}\right.$; see reaction 3 ) compared with those for protonation $\left(\mathrm{R}_{x} \mathrm{H}^{+}\right.$; see reaction 1). In terms of the reaction rates (reactions $1 \mathrm{a}$ and 3a), it is anticipated that $\left[\mathrm{R}_{y} \mathrm{H}^{+}\right]$increases with time relative to $\left[\mathrm{R}_{x} \mathrm{H}^{+}\right]$and, subsequently, the relative intensity of $[M-D]^{+}$increases with respect to $[M+$ $\mathrm{H}]^{+}$. With respect to the absolute intensities of the molecular ion species in FAB, this translates to a faster rate of decrease in intensity of $[\mathrm{M}+\mathrm{H}]^{+}$relative to $[\mathrm{M}-\mathrm{D}]^{+}$, as shown in Figure 4. A similar situation is observed with the $[\mathrm{M}-\mathrm{H}]^{+}$species in Figure 4, which decreases less rapidly than $[\mathrm{M}+\mathrm{H}]^{+}$, indicating a relative promotion of the hydride abstraction reaction. Although still present, the effect on relative $[\mathrm{M}-\mathrm{H}]^{+}$ and $[\mathrm{M}+\mathrm{H}]^{+}$intensities with time for the nondeuterated acetals is much less significant (Table 3 ) as $k_{2}>k_{1}$. The time dependence of the molecular ion species in FAB indicates that at least some of the reactive ionic precursors are generated in the condensed phase by fast-atom beam-induced ionization. Fast-atom beaminduced ionization processes have been proposed by several investigators $[8,9,14,22,23,281$. Preformation of the molecular ion species before FAB is not expected to account for the absolute ion intensities obtained in $\mathrm{FAB}$ because both $\mathrm{MB}$ and cyclic acetals have $\mathrm{pH}$ values of approximately $\sim 7[8,9]$. It is certainly difficult to interpret the time-dependent FAB (MB) results in terms of a gas-phase ionization model. 
Interestingly, for 4-decyl-2-phenyl-1,3-dioxolane-2-d (8), a significant time effect for $[M-D]^{+}$relative to $\left[\mathrm{M}+\mathrm{H}^{+}\right.$is not observed in FAB (MB) (Table 3). Instead, $[\mathrm{M}-\mathrm{D}]^{+}$is the major molecular ion for the duration of the experiment. This may be due to the increased surface activity of thus cyclic acetal compared with compounds 4 and 6 , where the effect of increased rate of formation of $\mathrm{R}_{y} \mathrm{H}^{+}$with respect to $\mathrm{R}_{x} \mathrm{H}^{+}$on $\mathrm{FAB}$ is more quickly reflected by the [M$D]^{+}:[\mathrm{M}+\mathrm{H}]^{+}$ratio (Table 3 ). Hence, for compounds 4 and 6, an important component of the time dependence observed for the respective molecular ion species (Table 3 ) could be the time required for the bulk-accumulated reaction products due to the $F A B$-induced reactive species to appear near the surface. The presence of lower intensity matrix-derived peaks in $F A B$ (MB) for compound 8 with respect to compounds 4 and 6 under similar experimental conditions suggests a greater surface activity for this compound. An alternative explanation of the domination of $[\mathrm{M}-\mathrm{D}]^{+}$in FAB (MB) for 4-decyl-2-phenyl-1,3-dioxolane-2-d (8) is that steric hinderance by the long alkyl chain makes protonation less competitive with $\mathrm{D}$ abstraction; however, bccause the 4-decyl-2-phenyl-1,3-dioxolane$2-d(8)$ is less soluble than its lower homologues, the former explanation is preferred.

The proposed surface concentration effect for 4decyl-2-phenyl-1,3-dioxolane-2-d (8), relative to 4butyl-2-phenyl-1,3-dioxolane-2-d (4) and 4-hexyl-2phenyl-1,3-dioxolane-2-d (6), may also help explain the difference in time profiles for compounds 4 and 6 in FAB (MB) and FAB with no supporting matrix (Table 3). The domination of the $[M-D]^{-1}$ molecular ion species for the pure 2-d acetals for the duration of the $\mathrm{FAB}$ experiment may be a direct consequence of the increased surface concentration of the cyclic acetals in these experiments relative to those in an MB matrix. Only small concentration effects are observed on the relative molecular ion intensities for the nondeuterated acetals by FAB (Table 3 ), which is thought to be a consequence of a larger rate constant for hydride abstraction $\left(k_{2}\right)$ in the condensed phase compared with that for protonation $\left(k_{1}\right)$. Further studies of concentration effects on FAB data for cyclic acetals dissolved in a variety of liquid matrices, including $\mathbf{M b}$, are presently in progress. Initial results are consistent with the mechanistic interpretations on FAB ionization processes tor the cyclic acetals presented in this work.

\section{Conclusion}

In this study, the FAB data for cyclic acetals, where predominant $[\mathrm{M}-\mathrm{H} / \mathrm{D}]^{+}$molecular ion formation occurs almost exclusively, were compared with EI and $\mathrm{CI}$ data to ascertain whether ionization in FAB for these compounds is mainly a gas-phase or condensedphase process. The absence of a significant $\mathbf{M}^{-+}$peak in FAB suggests that EI-type processes are not responsible for $[\mathrm{M}-\mathrm{H} / \mathrm{D}]^{+}$formation in FAB. In CI, [M -
$\mathrm{H}^{+}$formation is only competitive with protonation when methane is used as the reagent gas, so on the basis of this and gas-phase thermodynamic considerations, ionization on FAB of the cyclic acetals cannot be explained in terms of the gas collision model. Differences in the $\mathrm{CI}$ and $\mathrm{FAB}$ fragmentation patterns reinforce the belief that the two ionization processes are not analogous for the cyclic acetals. Hence, a condensed-phase ionization model has been proposed for FAB, where the solvation energy term is proposed to be responsible for the favoring of hydride abstraction over protonation for the nondeuterated cyclic acetals. On labeling, however, the situation is not straightforward because a dramatic time dependence is seen for the relative molecular ion intensities in FAB for the acetals with shorter alkyl chains (compounds 4 and 6 ). These observations can be rationalized in terms of kinetic isutope effects and fast-atom beam-induced processes in the condensed phase. Surface activity considerations can also be incorporated into this scheme to explain the $F A B$ data for the deuterated acetal with a longer alkyl chain (compound 8) as well as those results obtained for the pure acetals. These data thus provide interesting mechanistic implications for the formation of $[\mathrm{M}-\mathrm{H}]^{+}$species in FAB. In addition, elements of the discussion may well relate to the ionization processes involved in FAB for a broader base of compounds. We are presently studying molecules containing more basic groups with their structure that yield $[\mathrm{M}-\mathrm{H}]^{+}$in $\mathrm{FAB}$ to possibly expand the proposed ionization mechanisms to other families of compounds.

\section{Acknowledgment}

The authors gratefully acknowledge the financial support of the Natural Sciences and Engineering Research Council of Canada and Fonds FCAR (Government of Quebec).

\section{References}

1. Barber, M.; Bordoli, R. S.; Sedgwick, R. D.; Tyler, A. N. I. Chem. Soc. Chem. Commun. 1981, 325-327.

2. Barber, M.; Bordoli, R. S.; Elliut, G. J.; Sedgwick, R. D.; Tyler, A. N. Anal Chem. 1982, 54,645A-657A.

3. Wong, S. S.; Röllgen, F. W. Nucl. Instrum. Methods 1986, B14, 436-447.

4. Sunner, J-; Ikonomou, M. G.; Kebarle, P. Int. I. Mass Spectrum. Ion Processes 1988, 82, 221-237.

5. Ligon, W. V.; Dorn, S. B. Int. I. Mass Spectrom. Ion Processes 1986, 78, 99-113.

6. De Patw, E. Adv. Mass Spectrom. 1988, 11, 383-398.

7. Benninghoven, A. Int. I. Mass Spectrom. Ion Phys. 1983, 53, $85-99$.

8. Todd, P. J. Org. Mass Spectrom. 1988, 23, 419-424.

9. Todd, P. J. J. Am. Soc. Mass Spectrom. 1991, 2, 33-44.

10. Barber, M.; Bordoli, R. S.; Sedgwick, R. D.; Tetler, L. W. Org. Mass Spectron. 1981, 16, 256-260.

11. Cooks, R. G.; Busch, K. L. Int. J. Mass Spectrom. Ion Phys. 1983, 53, 111-124. 
12. Perreault, H.; Bertrand, M. J. Proceedings of the 36th ASMS Conference on Mass Spectrometry and Alled Topics; San Franrisro, $C A, 1988 ; p 61$

13. Sunner, J. A.; Kalutunga, R.; Kebarle, P. Anal. Chem. 1986, 58 , 1312-1316.

14. Sunner, J.; Morales, A.; Kebarle, P. Anal. Chem. 1987, 59, 1378-1383.

15. Schroder, E.; Munster, H.; Budzikiewicz, H. Org. Mass Spectrom. 1986, 21, 707-715.

16. Munster, H.; Theobald, F.; Budzikiewiç, H.; Schroder, E. Int. J. Mass Spectrom. Ion Processes 1987, 79, 73-79.

17. Huang, Q.-W.; Wut G.-L; Tang, H.-T, Int. I. Mass Spectrom. Ion Processes 1986, 70, 145-152.

18. Banditelli, G.; Bandini, A. L.; Pacchioni, G.; Minghetti, G.; Seraglia, R.; Traldi, P. Org. Mass Spectrom. 1991, 26, 945-950.

19. Shiea, J.; Sunner, J. Int. J. Mass Spectrom. Ion Processes 1991, $109,265-278$.

20. Johnstone, R. A. W.; Lewis, I. A. S.; Rose, M. E. Tetrahedron 1983, 39, 1597-1603.

21. Bonas, G.; Bosso, C; Vignon, M. R. Rapid Commun. Mass Spectrom. 1988, 2, 88-89.

22. De Pauw, E. Anal. Chem. 1983, 55, 2195-2196.

23. Didonato, G. C.; Busch, K. L. Antal. Chim. Acta 1985, 171, 233-239.

24. Bartmess, J. E.; Phillips, L. R. Anal. Chem. 1987, 59, 2012-2014.

25. Caprioli, R. M. Anal. Chem. 1983, 55, 2387-2391.

26. Connolly, M. J.; Orth, R. G. Anal. Chem. 1987, 59, 903-908.

27. Shiea, J.; Sunner, J. Org. Mass Spectrom. 1991, 26, 38-44.

28. Clayton, E.; Wakefield, A. J. C. J. Chem. Soc. Chem. Commun. 1984, $969-970$.

29. Duffin, K. L; Busch, K. L. Procedings of the 36 th ASMS Conference on Mass Spectrometry and Allied Topics; San Francisco, CA, 1988; p 765.

30. Takayama, M.; Fukai, T.; Nomura, T.; Nojima, K. Rapid Commun. Mass Spectrom. 1989, 3, 4-6

31. Rusen, R. T.; Hartman, T. G.; Rosen, J. D.; Ho, C-T. Rapid Commun. Mass Spectrom. 1988, 2, 21-23.
32. Curcuruto, O.; Traldi, P.; Moneti, G.; Corda, L.; Podda, G. Org. Mass Spectrom. 1991, 26, 713-717.

33. Takayama, M.; Fukai, T.; Nomura, T.; Nojima, K. Int. I. Mass Spectrom. Ion Processes 1990, 96, 169-179.

34. Paul, G. J. C.; Bourg, S.; Bertrand, M. J. Rapid Commun. Mass Spectrom. 1992, 6, 85-88.

35. Zha, Q.; Bailey, M. D.; Bertrand, M. J. Can J. Appl. Spectros. 1990, 35, 141-148.

36. Kiremire, B. T.; Chiarello, D.; Traldi, P.; Bravo, P.; Resnati, G. Rapid Commun. Mass Spectrom, 1991, 5, 591-595.

37. Baldwin, M. A.; Welham, K. J.; Toth, I.; Gibbons, W. A. Org. Mass Spectrom. 1988, 23, 697-699.

38. Johnson, W. S.; Rogier, E. R.; Szmuszkovicz, J.; Hadler, H. I.; Ackerman, J.; Bhattacharyya, B. K.; Bloom, B. M.; Stalmann, L.; Clement, R. A.; Bannister, B,; Wynberg, H. I. Am. Chem. Soc. 1956, 78, 6289-6302.

39. Gross, M. L.; Chess, E. K.; Lyon, P. A.; Crow, F. W.; Evans, S.; Tudge, H. Int. 1. Mass Spectrom. lon Phys. 1982, 42, 243-254.

40. Marshall, J. I. B.; Williams, D. H. Tetrahedron 1967, 23, 321-333.

41. Sanders, R. A. Anal. Chem. 1983, 55, 1194-1197.

42. Konopski, L.; Maslosz, J. Org. Mass Spectrom. 1988, 23, 692-696.

43. Pihlaja, K.; Kuosmanen, 1.; Vainiotalo, P. Org. Mass Spectrom. 1988, 23, 770-776.

44. Bertrand, M.; Beynon, J. H.; Cooks, R. G. Int. I. Mass Spectromt. Ion Phys. 1972, 9, 346-350.

45. Harrison, A. G. Chemical Ionization Mass Spectrometry, CRC Press: Boca Raton, FL, 1983.

46. Kralj, B.; Kramer, V; Vrscaj, V. Int. J. Mass Spectrom. Ion Phys. 1983, 46, 399-402.

47. Bojesen, G; Maller, J. Int. I. Mass Spectrom. Ion Processes $1986,68,239-248$.

48. Renner, D.; Spiteller, G. Bioned. Mass Spectrom. 1986, 13, 401-404.

49. Dillow, G. W.; Kebarle, P. I. Am. Chem. Soc. 1988, 110, 4877-4882. 